\title{
A construção da confiança em experiências de hospitalidade mediadas pela internet: os casos do Airbnb e do Couchsurfing
}

\section{The trust building in hospitality experiences mediated by the internet: the cases of Couchsurfing and Airbnb}

\author{
Ramon Bezerra Costa ${ }^{1}$ \\ Viviane Marinho Fernandes ${ }^{2}$ \\ Fernando do Nascimento Gonçalves ${ }^{3}$
}

Resumo: A partir da premissa da importância da confiança nas relações econômicas e de consumo, este artigo se dedica a refletir sobre os processos de construção da confiança em relações de consumo que se dão no campo da hospitalidade. Tal reflexão é feita a partir das experiências do Airbnb e do Couchsurfing, plataformas que permitem receber estranhos em casa ou se hospedar na casa de desconhecidos pagando ou não por isso. Essas práticas vão nos interessar por indicarem relações de consumo que parecem extrapolar as experiências ordinárias de compra e venda e evidenciar a formação de outros tipos de laços sociais, cuja construção o texto pretende analisar.

Palavras-chave: consumo; confiança; Airbnb; Couchsurfing.

\begin{abstract}
Starting from the premise of the importance of trust in economics and consumer relations, the present study reflects on trust building process in hosting consumer relations. This reflection is based on the Airbnb and Couchsurfing web platforms that allow any person to host strangers or to be hosted by not known people in their own houses (with or without payments). This kind of

1 Universidade Federal do Maranhão. Maranhão, MA, Brasil. E-mail: ramonbzc@gmail.com 2 Universidade Federal do Rio de Janeiro. Rio de Janeiro, RJ, Brasil. E-mail: vivianemf@gmail.com 3 Universidade do Estado do Rio de Janeiro. Rio de Janeiro, RJ, Brasil. E-mail: goncalvesfernandon@gmail.com
\end{abstract}


68 A CONSTRUÇÃO DA CONFIANÇA EM EXPERIÊNCIAS DE HOSPITALIDADE...

practices interest us by the consumer relations which appears overstep the ordinary buy-and-sell and make clear the formation of other social bonds whose constructions this paper intends to analyze.

Keywords: consumer; trust; Airbnb; Couchsurfing. 


\section{Sobre a questão da confiança}

A confiança parece uma questão fundamental nas relações econômicas e de consumo. Sua importância pode ser evidenciada por diversos estudos (FUKUYAMA, 1996; FINURAS, 2013; GIDDENS, 1991; SIMMEL, 2004; ZAK, 2012, entre outros) e pelo crescente interesse por índices que a mensuram estatisticamente. ${ }^{4}$ Essas construções estatísticas tornam-se importantes sinalizadores para avaliar a conjuntura, buscar tendências e tentar prever eventos futuros da economia. Como sinalizou Porter (1995), as estatísticas estão ligadas à constituição de conhecimento público, produzindo estreita relação entre números sociais e ação pública, uma relação que leva à criação e divulgação de medidas padronizadas e índices.

Os índices de confiança são construídos por diferentes instituições e relacionados a diferentes aplicações e distinguem-se segundo a metodologia desenvolvida e os cálculos estatísticos empregados. Comumente, mede-se a confiança do consumidor e de empresários com relação ao futuro das atividades econômicas, mas também se mede a confiança das pessoas nas instituições, a confiança em marcas, a confiança dos cidadãos em relação a governos ou partidos políticos ou mesmo o grau de confiança das pessoas em grupos sociais (como amigos, familiares e vizinhos). ${ }^{5}$

O interessante na construção desses indicadores, que buscamos destacar aqui, é o entendimento da confiança como uma variável mensurável. Não é raro que indicadores que meçam o grau de confiança das pessoas em determinadas situações (como na manutenção do emprego ou no pagamento de dívidas) e em determinadas instituições (como nas empresas, em instituições financeiras ou mesmo no governo) sejam apresentados na mídia acompanhados por análises e previsões desenvolvidas

4 Restringindo ao cenário brasileiro, alguns indicadores de confiança: o Índice de Confiança da Indústria e o Índice de Confiança de Serviços, medidos pela FGV; o Índice de Confiança do Empresário do Comércio, medido pela Confederação Nacional do Comércio; e o Índice de Confiança do Consumidor Exame GfK.

5 O Índice de Confiança Social, elaborado pelo Ibope, mede a confiança em diferentes setores da sociedade, quantificando a confiança em instituições das esferas pública e privada, bem como da sociedade civil. 
por "especialistas da economia"6 (NEIBURG, 2010, p. 3). No entanto, afastando-nos da naturalidade com que hoje podemos perceber esses números, pareceu pertinente perguntar sobre os modos de construção dessas medidas, as formas como são monitoradas, bem como os efeitos que produzem. Notamos que, a partir dos índices, a confiança ganha visibilidade e que, ao ser concebida a partir de uma abordagem metrológica, ajusta-se ao modo privilegiado por nossas sociedades de conceber a realidade (CROSBY, 1999). A confiança, quando associada a uma escala ou transformada em número, ganha uniformidade e parece afastar-se de seu aspecto pessoal e íntimo. A partir do número, a confiança parece adquirir precisão e, ao ser mensurada, padroniza-se e manifesta-se através de uma unidade que a dimensiona e permite equiparações.

Ao nos perguntarmos sobre esses índices de confiança, a ideia não é confrontar a validade desses indicadores e a eficácia de suas medidas, mas enfatizar a importância da confiança como um elemento ao mesmo tempo técnico e social capaz de influenciar ações. Produzidos e estudados por especialistas de diferentes áreas, o que esses índices tendem a revelar é que determinados comportamentos variam segundo o grau (maior ou menor) de confiança. Assim, ao monitorar essas medidas, busca-se identificar tipos de comportamentos, prever ações de diferentes agentes, correlacionando confiança e decisões futuras. Chamar atenção para esse fato é colocar em evidência a confiança como elemento significativo nas relações sociais.

A confiança entre as pessoas é um elemento primordial para a integração da sociedade (SIMMEL, 2004, p. 191). Anthony Giddens (1991) propõe encarar a confiança relacionada ao risco. Por exemplo, ao entrar em um avião ou depositar o dinheiro em um banco, confia-se em dinâmicas que organizam esses funcionamentos e minimizam os riscos; ainda que perigos não deixem de existir e que os conhecimentos sobre o funcionamento desses sistemas estejam em poder de "peritos". Diante disso, a confiança, para Giddens (1991), funciona como um ato

6 Essa expressão se refere a profissionais especializados em economia e/ou encarregados de diagnosticar e operar o sistema econômico e financeiro: acadêmicos, jornalistas, investidores, funcionários de governos. 
consciente de acreditar em algo a partir do conhecimento das situações de risco e também de algumas garantias.

A confiança, assim, está presente em práticas cotidianas, seja na compra de um leite de determinada marca, por acreditar na qualidade daquele produto, seja ao dirigirmos nosso carro e acreditarmos que o outro não conduzirá seu automóvel em direção ao nosso propositalmente. Estabelecemos o tempo todo relações sociais que exigem confiança e forjamos uma convicção no outro. Rotineiramente, suspendemos nosso ceticismo e nos convencemos de que é seguro estabelecer uma relação. Essa convicção, muitas vezes, apoia-se em razões particulares, mas estas não explicam completamente esse sentimento.

Porém, para além das marcas que adquirimos habitualmente e dos serviços que já nos acostumamos a utilizar, é curioso notar a emergência de experiências de consumo que parecem exigir mais confiança do que estamos habituados a conferir. Falamos isso pensando no mercado formado por plataformas na internet que permitem a viajantes encontrarem anfitriões dispostos a recebê-los, pagando ou não por isso, e oferecendo a casa inteira ou apenas um cômodo - relações essas entre completos desconhecidos.

Exemplo disso é o HomeExchange, um serviço de troca de casas. Quando lançado, em 1992, permitia, por meio de cartas, que os viajantes trocassem hospedagens. Pensado como um modelo alternativo às acomodações em hotéis, propunha reduzir os custos de hospedagem (principalmente para as viagens em família) e possibilitar a descoberta dos lugares a partir de uma perspectiva local. Com o advento da internet, o serviço migrou para um modelo mais próximo das redes sociais. A partir de uma plataforma on-line, os membros divulgam suas casas e tornam-se, ao mesmo tempo, hóspedes e anfitriões. Funciona assim: uma pessoa se estabelece na casa de alguém enquanto seu anfitrião se hospeda em sua residência. A iniciativa, no entanto, não é única: outras 
plataformas oferecem serviços parecidos, como o GuestToGuest.com, o Roomorama.com, o LoveHomeSwap.co e o Knok.com. ${ }^{7}$

Esse tipo de empresa e modelo de negócio, embora seja recente, tem crescido e exibe números significativos. Talvez o mais expressivo seja o Airbnb.com, que surgiu em 2008 e permite alugar, por temporada, apartamentos e casas (ou apenas quartos), além de opções mais singulares, como castelos, cavernas, iglus, casas de árvore e barcos. Tudo isso a preços tão diversos quanto as possibilidades de hospedagem, podendo custar menos que um albergue ou mais que um hotel de luxo.

O Airbnb tem escritórios em diversas cidades do mundo para administrar milhões de acomodações em mais de 34 mil cidades usadas por mais de 60 milhões de pessoas (QUEM SOMOS, 2016). Somente no Brasil, já existem mais de 70 mil acomodações cadastradas na plataforma - um crescimento de 67\% com relação a 2015 (INFOMONEY, 2016). A receita da empresa é oriunda das taxas sobre cada transação. É deduzida uma porcentagem dos pagamentos recebidos pelo anfitrião e é adicionada outra porcentagem aos pagamentos dos hóspedes. Atualmente, a empresa tem valor de mercado avaliado em US\$ 25 bilhões (BORNELI, 2015).

Já o Couchsurfing.com, criado em 2004, quatro anos antes do Airbnb.com, é uma das primeiras e mais expressivas plataformas de hospedagem, cuja peculiaridade reside em não efetuar nenhum tipo de cobrança monetária de seus usuários e estar, principalmente, focada na troca cultural que pode existir a partir da interação entre desconhecidos. Atualmente, segundo as informações divulgadas pela empresa, seu site reúne cerca de 12 milhões de pessoas em mais de 200 mil cidades (ABOUT US, 2016).

É curioso o fato de tantas pessoas estarem confiando em desconhecidos a ponto de hospedá-los em casa, estando ou não presentes. Independentemente dos motivos apresentados por essas pessoas para agirem dessa forma - seja a vontade de fazer amigos, a troca cultural ou

7 O site HomeExchange.com passou a atuar em vários países, contando com uma equipe global de aproximadamente 50 pessoas. Lançou sua versão em português, TrocaCasa.com, em 2006. Disponível em: https://www.trocacasa.com/pt/. Acesso em: 12 abr. 2016. 
o dinheiro extra proveniente do aluguel -, a confiança aparece como um elemento fundamental nessas experiências.

A confiança, nesses casos, não é apenas um índice adotado pelo mercado para mensurar a relação entre as pessoas, mas a condição de possibilidade desses modelos de negócios. A confiança, em plataformas como o Airbnb e o Couchsurfing, parece sugerir a existência de mais do que a simples disposição para investir ou consumir, e sim uma predisposição de se relacionar e confiar no outro a ponto de deixá-lo ficar em sua casa, usar seus objetos pessoais, conviver com você e sua família e dormir no cômodo ao lado do seu como se fosse um conhecido. Que relação é essa e como ela se dá?

Diante desse cenário, voltamos à pergunta inicial sobre a construção da confiança, que precisa ser delimitada. Assim, o problema ao qual nos dedicaremos aqui trata da confiança construída ou requerida em experiências de consumo que se dão no campo da hospitalidade por intermédio das plataformas citadas. Dessa maneira, a proposta deste artigo é analisar a maneira pela qual se constrói a confiança no Airbnb e no Couchsurfing. Como será apresentado, essas plataformas apoiam-se em diferentes processos e mecanismos de construção da confiança para proporcionar outras relações entre os sujeitos consumidores. Tais iniciativas foram escolhidas por serem as mais expressivas desse modelo de negócios.

\section{Consumo, hospitalidade e intimidade}

Simmel (2005), ao analisar a metrópole do início do século XX, falava da dificuldade dos indivíduos se adaptarem à intensificação dos estímulos nervosos e das interações às quais se expunham. Para o autor, a vida na cidade pequena seria marcada por interações mais habituais, nas quais as pessoas poderiam estabelecer vínculos mais profundos e construir relações pautadas pelo sentimento. Em oposição a esse modelo, a vida na cidade grande seria marcada pela reunião de pessoas com interesses distintos, por uma agitação nervosa, uma ambiência de estímulos contrastantes e por frequentes mudanças, exigindo, desse modo, 
que o indivíduo alterasse seu modo de vida: em vez de manter relações sólidas, mostrava-se necessário forjar relações mais superficiais. Afinal, como esclarece Simmel (2005, p. 582), em um círculo ampliado, não seria possível estabelecer relações profundas com todos os indivíduos; não seria possível responder à enorme quantidade de estímulos da cidade grande com o mesmo comportamento com que se conduz a vida na cidade pequena. O sujeito da metrópole se relacionaria de uma maneira mais impessoal, não reagiria mais com a alma, mas com o intelecto. Valer-se-ia de uma postura de reserva para alcançar um distanciamento das coisas e das pessoas.

Atento ao fenômeno de adaptação das pessoas à vida na metrópole, as relações econômicas que se estabeleciam foram foco de grande atenção de Simmel. O autor argumenta que a economia monetária facilitava as relações mais superficiais entre as pessoas. A relação produtor-consumidor seria um exemplo no qual se evidenciaria o distanciamento entre as pessoas - esses agentes não mais se reconheceriam mutuamente.

A cidade grande vivenciada e descrita por Simmel apresenta as pessoas estabelecendo relações não mais restritas geograficamente ou limitadas a grupos familiares ou círculos de conhecidos. Contudo, se as relações, naquele momento, se tornavam mais amplas, o contato com o outro, em contrapartida, era marcado pela indiferença e estranheza. Para enfrentar as condições impostas pela cidade grande, fora necessário encontrar formas de tornar as relações mais precisas, mais seguras, e procurou-se uma "objetividade no tratamento de homens e coisas" (SIMMEL, 2005, p. 579). Essa análise de Simmel é corroborada por Anthony Giddens (1991), que, seguindo na esteira do filósofo alemão, afirma que a confiança está fundamentalmente envolvida com as instituições da modernidade. Em meio à grande diversidade própria da cidade grande é que emergiu a necessidade de contratos e instituições capazes de produzir garantias, ou seja, construir a confiança entre os estranhos.

Francis Fukuyama (1996), economista político norte-americano, corrobora essa ideia ao afirmar que “[...] pessoas que não confiam umas nas 
outras acabarão cooperando somente num sistema de regras e regulamentos, que têm de ser negociados, acordados, litigiados e postos em vigor muitas vezes por meios coercitivos" (FUKUYAMA, 1996, p. 43). Conhecemos e estamos acostumados com os mecanismos contratuais que regulam a confiança entre desconhecidos em nossa sociedade. Instituições como cartórios e objetos como carimbos conferem sentidos a papéis e nos permitem ter garantias nas transações que realizamos. Contudo, o que pensar e/ou o que implica confiar no contexto das experiências de empresas como o Airbnb e o Couchsurfing, nas quais as relações de consumo que envolvem confiança e intimidade parecem construir e mensurar a confiança de outras formas?

Para muitas pessoas, alugar uma casa por temporada ou receber um parente distante ou um amigo de um amigo para passar alguns dias em casa já não é novidade. No entanto, o que o Airbnb e o Couchsurfing fazem, bem como outras iniciativas similares, é sistematizar e ampliar esses costumes, possibilitando que mais pessoas se conectem através das práticas de hospedagem, a ponto de transformar determinadas experiências em modelos de negócios rentáveis. Através dos mecanismos criados por Airbnb e Couchsurfing, é possível alugar (ou oferecer gratuitamente) um imóvel, contemplando a casa inteira, mas também um quarto ou somente um colchão na sala, permanecendo-se, nesses casos, na residência junto com o hóspede/cliente, compartilhando espaços e até mesmo a rotina da casa. Nessas iniciativas, as transações (pagas ou não) são organizadas por uma plataforma que funciona como "vitrine" dos espaços disponíveis, responsáveis também por criar estratégias visando construir e medir a confiança para que completos desconhecidos se sintam seguros a ponto de receber ou se hospedar com o outro. Essa última dimensão é a que nos interessa neste trabalho: compreender como se produz a confiança em quem se hospeda ou naquele a quem se solicita hospedagem.

Comecemos pelo Couchsurfing (CS), que se apresenta como uma comunidade global de viajantes dispostos a "compartilhar suas vidas de 
maneira profunda e significativa" e afirma ter como missão "fazer do mundo um lugar melhor a partir das viagens que enriquecem as conexões humanas" (ABOUT US, 2016). Em seu site, o CS apresenta cinco valores (OUR VALUES, 2016) que devem nortear as experiências que se dão por meio dessa plataforma: "compartilhe sua vida”, ou seja, compartilhe seu tempo, a casa, os objetos; "crie conexão", pois entendem que aceitar a bondade de desconhecidos fortalece a fé no outro e ajuda a tornar as pessoas melhores; "ofereça bondade", que inclui respeito, tolerância e valorização das diferenças; "fique curioso", ou seja, mantenha o desejo de aprender sobre o outro e seu mundo; "deixe melhor do que você encontrou", uma postura que se deve ter para com o mundo, os relacionamentos e a casa de seu anfitrião.

Já o Airbnb, que se define como um "mercado comunitário confiável para pessoas anunciarem, descobrirem e reservarem acomodações" (QUEM SOMOS, 2016), trabalha com o slogan "sinta-se em casa”, o que caracteriza a missão com a qual se apresenta: construir um "sentimento de pertença" e fazer com que os membros se sintam "acolhidos" e "seguros" em qualquer lugar do mundo desde que estejam usando o serviço (O MUNDO É A TUA CASA, 2016).

Tanto no Airbnb quanto no CS, para ser hóspede ou anfitrião, é necessário realizar um cadastro e elaborar um perfil com informações gerais, tais como: nome, e-mail, foto, cidade, línguas que fala, onde estudou e/ ou trabalha e uma apresentação pessoal; mas cada uma das plataformas tem suas especificidades de acordo com seu foco. No Airbnb, para quem quiser ser anfitrião, ${ }^{8}$ é necessário descrever em detalhes o lugar que está sendo oferecido: quantas pessoas suporta, se tem garagem, como é o bairro e o transporte na região, entre outras informações dessa natureza; além de postar fotos dos espaços. É necessário descrever também serviços extras que possam ser oferecidos aos hóspedes, tais como internet, café da manhã, TV, uso da cozinha etc.

Quem busca um lugar para se hospedar no Airbnb deve escrever a cidade de destino, as datas de chegada e partida e o número de hóspedes 8 É possível se cadastrar para ser apenas anfitrião, hóspede ou os dois. 
para encontrar as opções disponíveis. Interessante notar que, no Airb$\mathrm{nb}$, ao procurar um lugar para ficar, o resultado da busca coloca em destaque o imóvel e não o anfitrião. Há uma foto grande de algum cômodo da residência e, no canto inferior direito, uma pequena foto do anfitrião, paralela ao valor da diária daquele lugar. Ao contrário, no CS, o resultado da busca por cidade traz os anfitriões daquela localidade e não há fotos dos espaços, mas da pessoa. O foco não incide sobre avaliação espacial ou sobre o conforto do local, mas sobre a experiência de troca cultural com o outro, tanto que a proposta do site é oferecer o "sofá", ainda que muitos anfitriões ofereçam uma cama ou um lugar mais confortável.

Além das informações citadas anteriormente, no perfil do CS deve constar se "o sofá está disponível para receber pessoas" (é possível dizer "sim", "não" e "talvez") e se "aceita crianças ou animais de estimação". O perfil expõe ainda como é o cômodo no qual o hóspede vai dormir (colchão, cama, sofá, quarto individual ou compartilhado, sala) e se há uma preferência por hospedar pessoas do sexo masculino ou feminino, entre outras informações dessa natureza. O perfil do CS requer também a resposta de perguntas que tentam mostrar o estilo de vida da pessoa para que o hóspede, ao buscar um lugar para ficar, possa escolher alguém com quem tenha afinidade e que tenha vontade de conhecer, assim como o anfitrião, que deve ler o perfil do viajante e escolher se quer ou não hospedar aquela pessoa. As questões são: "missão de vida", “como participa do CS", "experiências no CS", "interesses", "filosofia”, "música, filmes, livros", "tipos de pessoas de que eu gosto", "ensine, aprenda, compartilhe”, "uma coisa incrível que vi ou fiz”, "opinião sobre o CS".

Diante do exposto e a partir de entrevistas com usuários(as) do Airbnb e do Couchsurfing e da observação participante realizada por um 
dos autores, parece-nos possível sugerir que a confiança na relação entre hóspede e anfitrião pode ser entendida a partir de um de seus sinônimos: o crédito. Acredita-se na reputação do outro, suspende-se, pelo menos em parte, as incertezas e crê-se no sucesso da relação. Confia-se no outro com a expectativa de que a experiência seja bem-sucedida. As descrições realizadas pelos próprios hóspedes e anfitriões, que dão origem aos perfis divulgados pelos sites, possibilitam escolher com quem se relacionar, provocam sentimentos como reconhecimento, afinidade ou mesmo curiosidade entre os usuários e, nesse sentido, produzem conexão e auxiliam no processo de construção da confiança.

\section{Construção da confiança no Airbnb e no Couchsurfing}

Com a popularização da internet a partir dos anos 1990, fomos, gradativamente, aprendendo sobre esse ambiente e elaborando outras maneiras de confiar em desconhecidos a partir das conexões oferecidas pelas redes digitais. Fomos acreditando que as pessoas com as quais interagíamos eram reais; realizamos compras em lojas on-line e demos os dados do nosso cartão de crédito confiando que não seriam divulgados; compramos não apenas em lojas conhecidas, mas também de pessoas estranhas pelo Mercado Livre ou pelo eBay; hoje, as formas de conexões entre estranhos aumentaram: estamos pegando carona, ${ }^{9}$ compartilhando refeições ${ }^{10}$ e enviando correspondências, ${ }^{11}$ além, é claro, de ficar na casa deles.

Como indicamos, tanto no caso do Airbnb quanto do Couchsurfing, as estratégias usadas para construir a confiança, garantindo assim seu modelo de negócios, são várias: perfil com informações pessoais (ambos); troca de mensagens entre anfitrião e hóspede (ambos); referências (ambos); verificação da identidade (ambos); vouchers (CS); anfitriões

9 Plataformas como blablacar.com e caronetas.com.br permitem oferecer e pegar caronas, dividindo ou não os custos, a partir de cadastro prévio.

10 Sites como o eatwith.com e o mealsharing.com permitem receber desconhecidos para uma refeição ou trocar um restaurante pela casa de um estranho.

11 Plataformas como o nimber.com e o meemeep.com conectam pessoas que precisam enviar alguma coisa de um lugar para outro com alguém que passará por aquele lugar de qualquer maneira. 
protegidos por seguro (Airbnb) e atendimento 24 horas (Airbnb). Vejamos cada uma delas.

Não é necessário preencher todas as informações pedidas em nenhuma das plataformas, mas uma quantidade maior de dados pode significar maior confiabilidade. O CS não se responsabiliza por qualquer situação que ocorra entre anfitrião e hóspede, mas oferece várias dicas que tentam contribuir com a segurança dos couchsurfers. Por exemplo: é aconselhado relacionar-se, prioritariamente, com pessoas que tenham os perfis completos, com nome real, fotos claras e descrições detalhadas de si mesmas. Obviamente, tais informações podem ser inventadas, porém, ainda assim, elas parecem ter um papel importante na construção da confiança. Outro elemento que parece também ser importante nesse processo é a empatia, capacidade psicológica de sentir o que o outro sentiria e se ver ou se colocar no lugar do outro. Há quem defenda que a empatia seria capaz de produzir, inclusive fisicamente, uma predisposição à confiança. De acordo com as pesquisas de Paul J. Zak (2012), que se dão no campo da neurobiologia em sua interface com a economia, a empatia produziria o hormônio ocitocina ou oxitocina, que tem a função de promover a confiança entre os indivíduos.

Longe de pensar os estudos de Zak e as formas de constituição dos vínculos de confiança no Airbnb e no CS do ponto de vista de um determinismo biológico, podemos supor, por exemplo, que seria possível alguém "se ver no outro", sentir empatia e confiar ao ler o perfil de outros usuários do CS ou do Airbnb e perceber que o outro gosta dos mesmos filmes, leu livros semelhantes e se descreveu usando argumentos e elementos afins aos seus. Em geral, o perfil do CS reúne mais informações pessoais que o do Airbnb, no entanto, é comum na troca de mensagens entre anfitriões e hóspedes eles trocarem os links dos seus perfis em redes sociais, o que permite saber mais sobre o outro, confiando mais ou não de acordo com a empatia construída.

Como já foi mencionado, antes de se hospedar ou receber alguém, em ambas as plataformas, é possível trocar mensagens para, por exemplo, solicitar mais informações, mitigar dúvidas, combinar detalhes e 
8O A CONSTRUÇÃO DA CONFIANÇA EM EXPERIÊNCIAS DE HOSPITALIDADE...

conhecer melhor o outro. Esse intercâmbio de informações costuma ser apontado pelas empresas como mais uma estratégia de construção da confiança, que também parece funcionar a partir da construção da empatia por meio das informações capazes de mostrar alguma característica do anfitrião ou do hóspede na qual o outro se reconheça.

Após cada estadia, tanto o anfitrião quanto o hóspede devem escrever uma referência sobre o outro, isto é, avaliar a experiência através de um pequeno texto que ficará exposto no perfil do avaliado e não poderá ser alterado ou apagado. As pessoas costumam falar tanto do espaço físico (no caso do Airbnb) quanto de como foi a experiência com o outro (em ambas as plataformas). É interessante notar o tom de pessoalidade das referências, mesmo entre pessoas que só se encontraram para trocar as chaves, como pode acontecer no Airbnb. Mais referências significa que mais pessoas já se hospedaram naquele lugar ou, então, que aquela pessoa já foi recebida em muitos lugares. Quanto mais referências positivas, melhor a reputação construída e, consequentemente, maior a confiabilidade. Ou seja, a cada indicação com menções positivas, mais fácil conseguir um sofá no Couchsurfing ou alugar um espaço no Airbnb.

É importante notar que as referências trocadas ficam visíveis a todos os usuários dessas plataformas. Essa ampla visibilidade das referências permite que o processo de avaliação não fique restrito aos hóspedes e anfitriões, mas esteja disponível a todos, aberto a diferentes interpretações. Uma vez que as referências não podem ser anônimas, verifica-se que não apenas essas avaliações recebidas têm um papel na construção da confiança, mas também as dadas. Por exemplo, se você se hospeda na casa de uma pessoa que já possui 30 referências positivas e, após a experiência, descreve sua avaliação de forma negativa, criticando algo que todas as outras pessoas disseram gostar, isso pode sugerir que o problema esteja com você e não com o outro, evidenciando que talvez você não seja um bom hóspede. O conjunto de informações disponíveis nos perfis dessas plataformas permite que seus usuários encontrem diferentes maneiras de interpretá-las, colocando-as em relação e confrontando-as. No caso do CS, tanto as referências que você recebeu quanto as que você 
deu ficam visíveis em seu perfil; dentro dessa dinâmica, entende-se que a forma como se fala do outro expressa também um pouco de si mesmo.

Curioso notar ainda que, nessas experiências, confia-se não apenas no anfitrião ou no hóspede, mas se acredita também no que pessoas igualmente desconhecidas falaram sobre eles. É como quando se compra um produto em uma loja on-line e se lê os comentários de quem diz já ter adquirido o produto, mas não se tem certeza se, de fato, falam a verdade.

Ao refletir sobre a importância desses comentários ou testemunhos, verifica-se o papel que a reciprocidade cumpre dentro dessas plataformas. O princípio da reciprocidade, sobre o qual tão detalhadamente escreveu Polanyi (2000), tem importância fundamental para a organização e a manutenção do funcionamento das plataformas que estudamos. No caso analisado, verifica-se que é preciso ser reconhecido como um bom hóspede ou bom anfitrião para continuar compartilhando plenamente os serviços. A importância de desempenhar bem seu papel não apenas garante uma boa experiência com o outro, mas também, na maioria das vezes, gera uma boa avaliação. Tal avaliação é como um "crédito" recebido em função de um bom comportamento, que será utilizado nas futuras interações. A reputação do usuário dentro da plataforma está totalmente conectada ao cumprimento das expectativas produzidas e relacionadas à condição de hóspede ou anfitrião. A relação social estabelecida será fundamental para a obtenção de uma boa avaliação e, consequentemente, a ampliação da confiança (ou do crédito) para novas utilizações.

Um dos fatores que favorece a reciprocidade no Airbnb e no CS é a simetria das relações. Como Polanyi (2000, p. 68) já havia sinalizado ao descrever alguns princípios socioeconômicos, "a reciprocidade é enormemente facilitada pelo padrão institucional da simetria”. Tanto no CS quanto no Airbnb existe uma simetria na relação entre hóspede e anfitrião que faz com que um dependa do outro para ser bem avaliado e, consequentemente, para continuar tendo êxito em compartilhar os serviços oferecidos pelas plataformas. Independente dos motivos que 
82 A CONSTRUÇÃO DA CONFIANÇA EM EXPERIÊNCIAS DE HOSPITALIDADE...

levam as pessoas a usarem o Airbnb e o CS, ao optarem por esse tipo de experiência, elas estão sujeitas ao princípio da reciprocidade - e tal modo de funcionamento da plataforma faz com que os atos dos participantes não sejam isolados. Dar e receber são comportamentos que adquirem a mesma importância. Saber dar e saber receber - e fazer isso bem - são virtudes, são comportamentos muito valorizados nas dinâmicas que observamos. Ser um bom anfitrião ou um bom hóspede requer que ambos compartilhem das regras de convivialidade estabelecidas sejam elas implícitas ou explícitas -, além de exigir o esforço de ambas as partes para cumprirem bem aquilo que é esperado delas. No caso dos hóspedes, podemos, por exemplo, citar o cuidado com a casa, o respeito pelos vizinhos, a gentileza. No caso do anfitrião, a recepção, a segurança e a observância das datas e horários marcados.

Ao retomar a descrição dos mecanismos de construção da confiança, vale destacar ainda que, em ambas as plataformas, é possível verificar a identidade do usuário. No CS, para essa verificação, é cobrada uma taxa opcional: mediante pagamento, a empresa certifica se o nome e o endereço residencial são reais. De fato, essa estratégia pode contribuir na construção da confiança, mas não parece ser uma das mais importantes, visto que, dos milhões de usuários cadastrados, menos de um milhão possui a conta verificada - existem usuários muito ativos, com mais de 100 referências, que não possuem a conta verificada.

No Airbnb, a verificação da conta é diferente: hóspedes e anfitriões conectam suas contas em plataformas como Facebook ou Gmail e digitalizam algum documento de identificação, como carteira de habilitação ou passaporte, e não é cobrado nenhum valor por isso. Todas as informações são mantidas em sigilo. Nessa plataforma, é possível falar em níveis de verificação, uma vez que o obrigatório para abrir a conta é cadastrar o e-mail (esse seria o primeiro nível); na medida em que o usuário oferece seu perfil em uma rede social ou documentos para verificação, ele gradualmente sobe níveis e aumenta sua confiabilidade.

O Couchsurfing tem ainda outra estratégia de construção da confiança que lembra a verificação, mas que é de total responsabilidade 
dos usuários: os vouchers, uma espécie de símbolo de confiabilidade adicionado ao perfil que significa "é seguro surfar neste sofá". Apenas o usuário que recebeu três vouchers pode contemplar outros usuários. Talvez devido a sua escassez, esse símbolo de confiabilidade parece ser o mais almejado da plataforma. Contudo, mesmo sem possuir esse "selo", é possível viajar e conseguir "sofás".

Ao aceitar um desconhecido em casa, uma das preocupações é quanto aos danos que podem ser causados por ele, especialmente quando se está ausente. Pensando nisso, o Airbnb oferece uma "garantia ao anfitrião”, que promete o reembolso de até $\mathrm{R} \$ 3$ milhões em caso de danos à propriedade. Qualquer reserva feita pelo site conta com essa garantia. Porém, o Airbnb ressalta que ela passa a valer nos casos em que os hóspedes causam danos que não são solucionados diretamente por eles próprios. Em geral, um copo quebrado é imediatamente reposto pelo hóspede. Assim, a proposta do Airbnb é que primeiro se entre em contato com o hóspede para solucionar o problema; caso isso não aconteça é que se deve recorrer à garantia.

No entanto, essa garantia não cobre perdas de dinheiro, animais de estimação, responsabilidade civil e áreas comuns ou compartilhadas. A empresa sugere que objetos como joias e obras de arte sejam guardados em cofres; no que diz respeito a perdas ou danos simples (como vidraça quebrada), os anfitriões podem implementar um depósito de segurança a cada reserva. Assim, essa "garantia ao anfitrião" cobre apenas situações graves, como possíveis incêndios.

Ainda na tentativa de oferecer um ambiente seguro às transações, o Airbnb tem outras estratégias para acompanhar e orientar os usuários, como as reuniões de orientação com os novos anfitriões e atendimento 24 horas por dia aos usuários.

Em ambas as experiências, vê-se que a confiança se dá a partir de uma construção coletiva, recíproca. As empresas, em seus sites, oferecem mecanismos que possibilitam conhecer o outro: um perfil detalhado, fotos, a possibilidade de troca de mensagens, um sistema de referências ou 
84 A CONSTRUÇÃO DA CONFIANÇA EM EXPERIÊNCIAS DE HOSPITALIDADE...

mesmo o serviço de verificação de identidade. No entanto, é imprescindível que hóspedes e anfitriões participem.

\section{Últimas considerações}

Diferente das avaliações de confiança que vimos no início do estudo, no Airbnb e no Couchsurfing estão ausentes sistemas de avaliação quantitativos. Diferente dos índices de confiança calculados e medidos de modo objetivo que almejam classificar níveis de confiança e traduzir experiências pessoais em formas numéricas ou alfanuméricas, ambas as iniciativas analisadas privilegiam a descrição e a qualificação das experiências. Ao descrever, recomendar, testemunhar, criam-se dinâmicas comunicativas e de constituição de laços que não parecem passar apenas por uma classificação fixa ou uma medida padronizada, mas pela construção e gestão permanente da confiança. Cada pessoa pode definir seus critérios e parâmetros, sendo possível, inclusive, não se preocupar com nenhum dos quesitos oferecidos pelo site ou tentar criar outros, como a indicação de amigos mais próximos e a elaboração de outras perguntas não previstas pelas plataformas.

Além das estratégias de construção da confiança citadas, é importante lembrar que essas empresas também investem no uso das chamadas redes sociais a fim de se tornarem conhecidas e terem suas marcas identificadas como confiáveis. Além disso, fazem frequente divulgação por meio de e-mails pessoais para os cadastrados nas plataformas. Do ponto de vista das relações de consumo, é importante observar que as campanhas comunicacionais das empresas costumam focar na construção de um "sentimento de pertença" entre os usuários, apostando em tom pessoal, marcado pela ideia de que essas plataformas são comunidades que permitem experiências únicas.

É interessante refletir sobre a utilização, tanto no Airbnb quanto no CS, do termo "comunidade" em suas estratégias de promoção, que parecem funcionar como vetor de atração e de confiança para novos usuários. Muitos autores já refletiram sobre as características comunitárias possibilitadas por ferramentas ou plataformas na internet (SMITH, 
1999; CASTELLS, 2003; RECUERO, 2009). O campo semântico sugerido pela palavra comunidade envolve, em diferentes níveis, pertencimento, proximidade, conhecimento, afinidade - qualidades que contribuem diretamente para a construção da confiança. No caso do Airbnb e do CS, observamos que tal conceito reforça duas qualidades dessas plataformas. Em um sentido, a aposta na ideia de comunidade reforça a proposta de integração a partir de interesses comuns. Através da rede social desenvolvida, as plataformas oferecem a possibilidade de ser estabelecida uma relação com o outro que compartilha de interesses semelhantes; seguindo esse raciocínio, a proposta de hospedagem pode ser entendida como uma proposta de conexão entre pessoas que buscam experiências diferentes daquelas oferecidas pelos hotéis. Comunidade, por outro lado, também se refere à integração espacial, no sentido de que se trata de um convite à casa, ao espaço do outro - um convite à experiência comum. Através do compartilhamento de espaços, essa conexão com o outro pode ser experimentada em diferentes intensidades.

O uso de redes sociais para divulgação de experiências positivas entre os usuários também é uma estratégia de promoção recorrente das plataformas. No caso do Airbnb, não raro são elaborados vídeos curtos que, de modo rápido e lúdico, enfatizam dados como o número de usuários cadastrados ou as cidades onde estão disponíveis os serviços. A divulgação de informações como essas contribui para colocar em evidência o tamanho e a capilaridade do serviço. Os muitos números utilizados expressam não apenas a dimensão alcançada pela iniciativa: endossam também a solidez do modelo de negócio, que, apesar de recente, tem expressiva quantidade de usuários e relevante valor de mercado, conforme foi citado. A segurança da plataforma é enfatizada ainda pela transparência da troca de informações, pelo serviço de garantia financeira e pela disponibilidade 24 horas da equipe de atendimento - esses elementos reunidos conferem legitimidade e autoridade para a prestação de serviço.

Conforme tratamos a partir de Simmel (2004), a confiança entre as pessoas é uma dimensão primordial para a integração da sociedade. 
Em um círculo ampliado de interações, as relações requisitaram maior precisão. Para o autor, a exatidão contábil trazida pela economia monetária predominou no espírito do indivíduo moderno (SIMMEL, 2005 , p. 580). Na maior parte das vezes, a confiança no outro, em um ambiente de perda dos vínculos pessoais, foi reestabelecida através de relações mais precisas e contratuais, a partir da criação de instituições e funções para desempenharem papéis que antes eram realizados por sujeitos dispersos, sem formalizações. Esse cenário que Simmel descreve ao observar o início do século XX parece se perpetuar até hoje. O que observamos com o Couchsurfing e o Airbnb revela, no entanto, uma espécie de "fresta" nesse modo de funcionamento prioritariamente objetivo. Essas iniciativas, de alguma maneira, parecem recolocar a ênfase nas relações pessoais a ponto de tomar a confiança entre as pessoas como a base de seu funcionamento, ainda que as interações aconteçam mediadas por empresas e suas garantias. As plataformas mediam o contato entre os usuários e conduzem estratégias que corroboram a construção da confiança, mas o modelo de negócio que constroem exigem vínculos outros, diferentes daqueles das interações basicamente comerciais.

Além disso, ambas as plataformas buscam construir uma integração privilegiando o "princípio da reciprocidade" (POLANYI, 2000). Ao proporcionar maior proximidade na relação entre hóspede e anfitrião, prezam pela construção de relações de consumo que não se forjam, unicamente, a partir das formalidades cliente-empresa, consumidor-fornecedor. Não é, prioritariamente, a moeda que intermedeia a relação de consumo e o que está em questão nessa relação não é simplesmente o consumo de um serviço. A lógica estabelecida fundamenta-se, principalmente, em uma relação de reciprocidade entre aquele que dá e/ ou recebe, em uma dinâmica de obrigações mútuas na qual ambos precisam cumprir bem seu papel - isto é, aquilo que se espera dele. A produção da confiança passa justamente pela observância das expectativas alheias e pela construção de uma reputação.

Acompanhando diferentes iniciativas de consumo caracterizadas por práticas de compartilhamento, observamos que essas se espalham para 
as mais diversas áreas: do transporte à alimentação, passando pelo turismo e pela educação. Em comum, tais experiências trazem a confiança como uma condição de possibilidade fundamental. Posicionam-se, desse modo, em algum lugar entre as relações pessoais - caracterizadas por suas imprecisões - e a economia de mercado - que privilegia a objetividade -, mas, sem dúvida, reorganizam o papel da confiança nas relações de consumo.

As práticas de consumo sobre as quais refletimos neste trabalho parecem fazer parte de modelos de negócios recentes e em expansão, como mostram os dados das empresas citados anteriormente e pesquisas divulgadas (COLLABORATIVE LAB, 2014). No entanto, da mesma maneira como, há tempos, nos acostumamos a comprar roupas e objetos em lojas de departamento em detrimento do alfaiate ou do artesão ou achamos normal estender a mão no meio da rua para pegar um táxi sem saber quem é aquela pessoa e para onde ela irá nos levar, parece-nos que tais práticas de consumo também podem se tornar habituais ou comuns. Ocorrendo ou não isso, devemos observar e investigar tais modos de fazer que são também modos de ser, pois eles parecem deixar visível a conexão entre mercado e vida pessoal, evidenciando, mais uma vez, que, nas relações de consumo, as práticas econômicas e a vida íntima não se encontram separadas.

\section{Referências}

ABOUT US. Couchsurfing. Disponível em: http://www.couchsurfing.com/about/about-us/ Acesso em: 26 mar. 2016.

BORNELI, J. Airbnb recebe novo aporte e se iguala a Petrobras e Vale em valor de mercado. Infomoney, 11 dez. 2015. Disponível em: http://startse.infomoney.com.br/ portal/2015/12/11/15591/airbnb-recebe-novo-aporte-e-se-iguala-a-petrobras-e-vale-em-valor-de-mercado/. Acesso em: 26 mar. 2016.

CASTELLS, M. A Galáxia da Internet. Reflexões sobre a Internet, os Negócios e a Sociedade. Rio de Janeiro: Zahar, 2003. 
COLLABORATIVE LAB. What do people really think?, a summary of findings across this year's studies on the collaborative economy. Collaborative Consumption. 2014. Disponível em: http://www.collaborativeconsumption.com/2014/12/18/ what-do-people-really-think-a-summary-of-findings-across-this-years-studies-on-the-collaborative-economy/. Acesso em: 27 mar. 2016.

CROSBY, A. A mensuração da realidade: a quantificação e a sociedade ocidental. São Paulo: Unesp, 1997.

FINURAS, A. P. M. C. Confiança nas instituições e valores culturais: estudo internacional comparado entre Angola, Cabo Verde, Moçambique e Portugal. 2013. 430p. Tese (doutorado em Ciência Política) - Faculdade de Ciências Sociais, Educação e Administração da Universidade Lusófona de Humanidades e Tecnologias, Lisboa, Portugal, 2013.

FUKUYAMA, F. Confiança: as virtudes sociais e a criação da prosperidade. Rio de Janeiro: Rocco, 1996.

GIDDENS, A. As consequências da modernidade. São Paulo: Unesp, 1991.

INFOMONEY. Crescendo com a crise, Airbnb investe no Brasil e se prepara para Olimpíadas. Uol Economia, 23 mar. 2016. Disponível em: http://economia.uol.com. br/noticias/infomoney/2016/03/23/crescendo-com-a-crise-airbnb-investe-no-brasil-e-se-prepara-para-olimpiadas.htm. Acesso em: 26 mar. 2016.

NEIBURG, F. Os sentidos sociais da economia. In: DIAS DUARTE, L. F.; BENEDITO M. C. (Orgs.). Antropologia. Horizontes das Ciências Sociais no Brasil. São Paulo: Anpocs: Ciência Hoje: Discurso Editorial: Barcarolla, 2010.

O MUNDO É A TUA CASA. Blog.Airbnb. Disponível em: http://blog.airbnb.com/ belong-anywhere-br/. Acesso em: 27 mar. 2016.

OUR VALUES. Couchsurfing. Disponível em: http://www.couchsurfing.com/about/values/. Acesso em: 26 mar. 2016.

POLANYI, K. A grande transformação: as origens de nossa época. Rio de Janeiro: Campus, 2000.

PORTER, T. M. Trust in Numbers: the pursuit of objectivity in science and public life. Reino Unido: Princeton University Press, 1995.

QUEM SOMOS. Airbnb. Disponível em: https://www.airbnb.com.br/about/about-us. Acesso em: 26 mar. 2016.

RECUERO, R. Redes sociais na internet. Porto Alegre: Sulina, 2009.

SIMMEL, G. As grandes cidades e a vida do espírito (1993). Mana. Estudos de antropologia social, (11)2, p. 577-591, 2005.

The philosophy of Money. Londres: Routledge, 2004.

SMITH, M. Invisible Crowds in cyberspace: mapping the social structure of Usenet. In: KOLLOCK, P.; SMITH, M. A. Communities in Cyberspace. Londres: Routledge, 1999. ZAK, P. J. A molécula da moralidade: as surpreendentes descobertas sobre a substância que desperta o melhor em nós. Rio de Janeiro: Elsevier, 2012. 
Ramon Bezerra Costa - Professor do Departamento de Comunicação da Universidade Federal do Maranhão. Mestre e doutor pelo Programa de Pós-graduação em Comunicação da Universidade do Estado do Rio de Janeiro.

Viviane Marinho Fernandes - Doutoranda pelo Programa de Pós-graduação em Antropologia Social do Museu Nacional da Universidade Federal do Rio de Janeiro.

Fernando do Nascimento Gonçalves - Professor do Programa de Pós-graduação em Comunicação da Universidade do Estado do Rio de Janeiro. Doutor em Comunicação pela Universidade Federal do Rio de Janeiro.

Data de submissão: 10/06/2016

Data de aceite: 04/12/2016 